Accepted for publication in Australasian Journal of Philosophy

After online publication, the published version will be available online at:

https://doi.org/10.1080/00048402.2019.1648532.

Date of acceptance: 15 July 2019

Date of manuscript: 29 June 2019

\title{
Perception, Mind-independence, and Berkeley
}

\section{Penelope Mackie}

University of Nottingham

penelope.mackie@nottingham.ac.uk

\begin{abstract}
I discuss a thesis that I call 'The Appearance of Mind-Independence', to the effect that, to the subject of an ordinary perceptual experience, it seems that the experience involves the awareness of a mind-independent world. Although this thesis appears to be very widely accepted, I argue that it is open to serious challenge. Whether such a challenge can be maintained is especially relevant to the assessment of any theory, such as Berkeley's idealism, according to which the only objects of which we are aware in perception are mind-dependent. But the issue is of significance for the philosophy of perception more generally. In the course of my sceptical discussion, I argue that recent work by Campbell and Cassam [2014] may be flawed by a failure to take sufficiently seriously the requirements for genuine mind-independence.
\end{abstract}

KEYWORDS: perception, perceptual experience, mind-independence, phenomenal character, Berkeley 


\section{Introduction: Berkeley and common sense}

In taking physical objects to be mind-dependent collections of ideas, Berkeley appears to be in conflict with common-sense beliefs about the physical world. Moreover, in spite of his protestations to be a defender of common sense, Berkeley himself appears to admit that there is a conflict, notably in the following notorious passage:

It is indeed an opinion strangely prevailing amongst men, that houses, mountains, rivers, and in a word all sensible objects have an existence natural or real, distinct from their being perceived by the understanding. [Principles 4]

Although Berkeley claims that this belief can readily be seen to involve 'a manifest contradiction', he appears here to concede that it is prevalent among ordinary people, and not merely philosophers. According to a standard interpretation, Berkeley thought this conflict with common sense a price worth paying for the retention of another commonsense belief: that in perception we are directly aware of physical objects [Tipton 1974: 546; Foster and Robinson 1985: 3; Robinson 1996: xiii-xiv, 232].

What I want to consider is whether, in addition to being in conflict with our ordinary beliefs about the status of the physical objects that we perceive, Berkeley's theory of physical objects as mind-dependent collections of ideas is also in conflict with our ordinary experience in perception.

I don't aim to defend Berkeleian idealism. But this question is of interest, not simply for the assessment of Berkeley's theory, but for the philosophy of perception more generally. Moreover, the question has recently gained prominence by the publication of a book 
discussing the relation between sensory experience and mind-independence: Campbell and Cassam's Berkeley's Puzzle [2014].

\section{The thesis of the Appearance of Mind-Independence (AMI)}

Is it the case that, if Berkeleian idealism is true, our ordinary perceptual experience is misleading as to the character of the world we perceive - misleading because it presents, or seems to present, that world as mind-independent, when in fact it is not? This is what I take the question whether Berkeleian idealism is 'in conflict' with our ordinary experience in perception to be. ${ }^{1}$

This question can be subdivided. On the one hand, we can ask whether Berkeley's theory is in conflict (in the sense indicated above) with what it is like for a subject to have an ordinary perceptual experience - what is sometimes called the experience's 'phenomenology', 'phenomenal character', or 'conscious character' [Siegel 2006b: 484, 2016: section 1; Martin 1997: 93; Soteriou 2016: 222]. There is such a conflict if the following thesis is true:

'Phenomenal character' version of the Appearance of Mind-Independence (AMI) thesis: Ordinary perceptual experience is (or involves) the presentation of objects and features as mind-independent.

\footnotetext{
${ }^{1}$ Thus my topic is not whether Berkeleian idealism is inconsistent with the occurrence of ordinary perceptual experiences. (See also section 2.1 below.)
} 
On the other hand, we can ask whether Berkeley's theory is in conflict (again in the sense indicated above) with the deliverances of introspection when we reflect upon the phenomenal character of our ordinary perceptual experience. There is such a conflict if the following thesis is true:

'Introspection' version of the Appearance of Mind-Independence (AMI) thesis: Ordinary perceptual experience has the AMI ('Appearance of Mind-Independence') property: that is, it appears to its subject that the experience is (or involves) the awareness of mindindependent objects and features. ${ }^{2}$

The two versions of the AMI thesis are subtly different. Roughly, the first is a claim about how the world seems to us when we have a perceptual experience (that it seems to be a mind-independent world), whereas the second is a claim about how the experience seems to us when we reflect upon it (that it seems to be of a mind-independent world).

I return to the issue of the relation between the theses shortly (section 2.2). Meanwhile, I want to emphasize that, in either of these versions, the AMI thesis is a claim about how things appear to the perceiver to be; not a claim about what the objects (if any) of which the perceiver is aware actually are. Hence the AMI thesis (in either version) could be true even if, as Berkeley maintains, we never perceive any mind-independent objects. According to the Berkeleian, if the AMI theses were true, our perceptual experience would be misleading

\footnotetext{
${ }^{2}$ This is to be read as implying that it appears to the subject that the experience presents the objects and features as mind-independent.
} 
as to the true nature of perception. But that does not entail that there is any inconsistency between the Berkeleian theory and the AMI theses. ${ }^{3}$

It appears to be widely believed that the AMI thesis, in one or other (or both) of the versions that I have distinguished, is true. Or at least, it appears to be widely believed that some such version of the AMI thesis is widely believed.

For example, it seems to be the AMI thesis, in its 'phenomenal character' version, that Tim Crane and Craig French attribute to 'our ordinary conception of perceptual experience' when they endorse the following thesis:

Mind-Independence: perceptual experience involves the presentation (as) of ordinary mind-independent objects [2017: section 1.1.1],

which they also express as the claim that 'perceptual experience is a presentation of, or is as of, a public, mind-independent subject-matter' [ibid.; italics omitted]. The qualification in the phrase 'presentation (as) of' is explained by Crane and French as allowing that a perceptual experience can satisfy (and not merely appear to satisfy) their MindIndependence thesis even if it is a pure hallucination [ibid.: section 1.1.2, final paragraph]. Matthew Nudds seems to take it for granted that the 'introspection' version of the AMI thesis is true, at least for visual perception:

In general ... when we introspect a visual experiential episode, it seems that we are related to some mind-independent object or feature that is present and is a part, or a constituent, of the experience. [2009: 334. Italics mine]

\footnotetext{
${ }^{3}$ See also section 2.1 below.
} 
Nudds adds that it is 'widely accepted that visual experiences seem to have' 'the property of having some mind-independent object or feature as a constituent' [ibid.: 334-5. Italics mine].

Further examples are not hard to find. According to Katalin Farkas, it 'is an integral part of the phenomenology of mature perceptual experience that it seems to present to us an experience-independent world' [2013: Abstract]. John Campbell appears to take it for granted that ordinary perceptual experience satisfies a version of the AMI thesis; for example, in saying: 'ordinary perceptual experience seems to provide us at every moment with crowds of mind-independent things' [Campbell and Cassam 2014: 29]. In the same work, Quassim Cassam is hospitable to the idea that 'the mind-independence of objects actually shows up in sensory experience' [ibid.: 165]. And Michael Martin speaks of 'the fact that our experience does manifestly present a mind-independent world' [2006: 406].

Widely accepted or not, however, we may question whether the AMI theses do accurately describe the phenomenology that our ordinary perceptual experiences have, or seem to us to have. And this is just what I shall question. Before proceeding, however, I must say more about the two versions of the AMI thesis, and a complication concerning Naïve Realism and phenomenal character.

\subsection{Naïve Realism, phenomenal character, and Berkeleian idealism}

According to some proponents of Naïve Realism, the phenomenal character of a veridical perceptual experience is constituted, in part, by (relations to) mind-independent objects and features. $^{4}$ (See, for example, Nudds [2009: 335]; Soteriou [2016: 65-6, 161]; cf. Martin

\footnotetext{
${ }^{4}$ I use 'Naïve Realism' in what is now its standard sense, to refer to a theory according to which
} 
[2002: 394-5].) On this view, it would not be possible to have an experience with that phenomenal character if Berkeleian idealism were true. These theorists are therefore committed to the thesis that the very occurrence of perceptual experiences with that phenomenal character is inconsistent with Berkeleian idealism.

I cannot, in this paper, attempt a refutation of this version of Naïve Realism on Berkeley's behalf. However, I want to emphasize that this form of Naïve Realism does not entail the 'phenomenal character' version of the AMI thesis. Even if ordinary (veridical) perceptual experiences do have a phenomenal character that is (partly) constituted by (relations to) mind-independent objects and features, it does not follow that the phenomenal character of these experiences involves the presentation of these (mind-independent) objects and features as mind-independent. Thus, those who hold this form of Naïve Realism are not thereby entitled to claim that the feature of mind-independence is part of (or a constituent of) the phenomenal character of even our veridical perceptual experiences. ${ }^{5}$

\subsection{Phenomenal character and introspection}

In giving two versions of the AMI thesis, I have attempted to accommodate a distinction between the phenomenal character of a perceptual experience, and the phenomenal character that the experience appears to its subject to have when the subject reflects on the experience.

According to many writers, a perceptual experience may possess a phenomenal character (there may be something it is like to have the experience) even if the subject does

veridical perceptual experience is essentially a relation to mind-independent objects and features, and is associated with a disjunctivist theory of perception.

${ }^{5}$ Cf. Cassam, in Campbell and Cassam [2014: 155-7]. 
not introspectively reflect on what that phenomenal character is. This provides one reason for distinguishing my two versions of the AMI thesis.

A further reason is that some proponents of Naïve Realism hold that the phenomenal character of a perceptual experience can be other than it appears to introspection to be. According to these theorists, a pure hallucination that is subjectively indistinguishable from a veridical perception appears to have a phenomenal character (that of a veridical perception) that it does not actually have. (See, for example, Nudds [2009: 335]; Soteriou [2016: chs 3 and 6].)

From now on, however, I shall generally ignore these complications, and focus on the 'introspection' version of the thesis. I shall take the AMI thesis to be the following:

The Appearance of Mind-Independence (AMI) thesis: Ordinary perceptual experience has the AMI ('Appearance of Mind-Independence') property: that is, it appears to its subject that the experience is (or involves) the awareness of mind-independent objects and features. ${ }^{6,7}$

My principal justification (apart from limitations of space) is that those who hold the 'phenomenal character' version of the AMI thesis typically appeal to the 'introspection'

\footnotetext{
${ }^{6}$ See note 2 above.

${ }^{7}$ Following many other writers, I use the expression 'ordinary perceptual experience' without defining it. I take it, though, that 'extraordinary' perceptual experiences would include cases in which it seems to its subject that the experience is an awareness only of figments of the subject's own mind or perceptual apparatus. I also assume that the topic is the ordinary perceptual experience of mature human adults.
} 
version as evidence for the phenomenal character version (for example, Crane and French $[2017])^{8}$

Now that it is clear what the Appearance of Mind-Independence (AMI) thesis that is my target asserts, we can proceed to consider whether the thesis is true. In order to do so, though, we need to know what the alternatives to the AMI thesis are. I approach this issue by considering what Berkeley's attitude to the thesis should be.

\section{The options for Berkeley}

\section{Option 1: Error theory}

As already indicated (section 2 above), one option for a Berkeleian idealist appears to be to accept the AMI thesis, and concede that it seems to us that in perception we are confronted with mind-independent physical objects, although in fact we never are. If Berkeley were to take this option, he would have to present his theory of perception as an error theory.

However, this error theory comes at a price. I do not have space to do justice to the relevant issues here. Most crucially, though, adopting this option would require Berkeley to relinquish one of his most cherished doctrines: that the way the world really is in itself is, broadly speaking, the way it appears to us in perception, and that in this respect his theory is in accord with common sense. ${ }^{9}$

\footnotetext{
${ }^{8}$ This is true even of those Naïve Realists mentioned above who think that introspection is not an infallible guide to phenomenal character [Nudds 2009: 335].

${ }^{9}$ Some may suppose that the error theory is not available to Berkeley, even as an inferior option, on the grounds that Berkeley denies that we even have the concept of a mind-independent physical object. (Cf. Campbell and Cassam [2014, passim].) However, I am not convinced that Berkeley
} 


\section{Option 2: reject the AMI thesis in favour of a thesis of the Appearance of Mind-}

\section{Dependence (AMD)}

A radical response on Berkeley's part would be to deny the AMI thesis, and assert, in its place, the following:

The AMD thesis: Ordinary perceptual experience has the AMD ('Appearance of MindDependence') property: that is, it appears to its subject that the experience is (or involves) the awareness only of mind-dependent objects and features.

However, although Berkeley himself might have been tempted by this option, ${ }^{10}$ I think it is very unattractive. It seems completely implausible to claim that a faithful description of the phenomenology of a typical perceptual experience - for example, that of viewing a landscape - would say that it appears to be an awareness only of things that are dependent on some mind for their existence. Rather than adopting this radical response, Berkeley would, I suggest, be better off taking a third way.

\section{Option 3: reject the AMI thesis in favour of Neutrality}

According to this third option, although our ordinary perceptual experience does seem to us (when we introspectively reflect upon it) to be or to involve the awareness of physical

unequivocally denies that we have the concept of a mind-independent physical object, as opposed to denying that we have a coherent concept of such an object.

${ }^{10}$ This interpretative issue is beyond the scope of this paper. 
objects and features, it does not seem to be or involve the awareness of them as mindindependent or as mind-dependent. This can be encapsulated in the following thesis:

The Neutrality thesis: Ordinary perceptual experience has the Neutrality property: that is, it appears to its subject that the experience is (or involves) the awareness of physical objects and features, but it is not the case that it appears to its subject that the experience is (or involves) the awareness of those physical objects and features as mind-independent or as mind-dependent.

If the Neutrality thesis is correct, then both the AMI thesis and the AMD thesis are incorrect.

Once the Neutrality thesis is on the table, however, I think this poses a significant challenge to the AMI thesis. Not only does the Neutrality thesis represent (I think) the best option for Berkeley; in addition, it is, I shall maintain, a serious rival to the AMI thesis, independently of the debate between Berkeley and his opponents.

So my next question is: how might one defend the AMI thesis - the thesis that an ordinary perceptual experience seems to its subject to involve the awareness of a mindindependent world - against the rival Neutrality thesis? In the next section, I consider three inadequate reasons for accepting the AMI thesis. The reason for this indirect approach is that, by considering these failures, it will become evident just how difficult is the task of defending the AMI thesis. 


\section{Three inadequate reasons for accepting the AMI thesis}

\subsection{Physical object concepts in introspective reports}

In a famous discussion of perceptual experience, P. F. Strawson observed that, if asked to report one's visual experience in a way that is faithful to the nature of the experience, one will describe it, not in terms of shapes or coloured patterns, but using terms that refer to ordinary physical objects, such as this:

'I see the red light of the setting sun filtering through the black and thickly clustered branches of the elms; I see the dappled deer grazing in groups on the vivid green grass . . $\therefore[1979: 43]$

Moreover (Strawson continues), even if asked to report one's experience in a way that (unlike the description just given) involves no commitment to the experience's being veridical - a report that would remain faithful to the nature of the experience even if it should turn out to be an illusion - one would still use a description in terms of sun, elms, deer, etc., but amend it to 'protect it' against falsification, by saying something like: "'I had a visual experience such as it would have been natural to describe by saying that I saw [the red light of the setting sun ... .], etc. ..."' [ibid.: 43-4. Italics mine].

Strawson concludes that in addition to the fact that '[o]ur perceptual judgements . . . embody or reflect a certain view of the world, as containing objects, variously propertied, located in a common space and continuing in their existence independently of our interrupted and relatively fleeting perceptions of them', 'it [now] appears ... that our sensible experience itself is thoroughly permeated with those concepts of objects which 
figure in such judgements' [ibid.: 44. Italics mine]. On this basis Strawson asserts what we can call his 'permeation thesis':

Sensible experience is permeated by concepts of . . realistically conceived objects. [ibid.: 45]

Strawson's discussion is often cited in support of the thesis that ordinary perceptual experience involves at least the appearance of an awareness of mind-independent objects that is, in support of the AMI thesis..$^{11}$ But it should be obvious that, if transported to a dialectical situation in which the opponent of the AMI thesis is a Berkeleian idealist, what Strawson says here is entirely inadequate as an argument for the thesis. Strawson simply assumes that the physical object concepts that he takes to 'permeate' our perceptual experience are concepts of physical objects 'realistically construed' - construed in a way that entails that they are mind-independent items, rather than, say, collections of ideas. Hence it is open to the Berkeleian to agree with Strawson that a faithful description of one's perceptual experience must employ physical object concepts - must describe it as an experience as of such things as the sun, elms, deer, etc. - while also denying that this faithful description requires a realistic construal of those physical object concepts.

That is not yet to say that Strawson is wrong in thinking that a faithful description of how a typical visual experience seems to its subject must involve concepts of physical objects construed 'realistically', as the AMI thesis implies. My point is just that Strawson provides no argument for this.

${ }^{11}$ See, for example, Nudds [2009] and Crane and French [2017]. 
Let us compare two versions of a 'permeation thesis': the Strawsonian version, according to which our sensible experience is permeated by concepts of mind-independent physical objects, and a 'neutral' version according to which it is permeated by concepts of physical objects that involve no commitment to the status of those physical objects as mindindependent or mind-dependent. ${ }^{12}$ I suspect that many who claim to find Strawson's observations compelling have failed to distinguish these, and to consider the possibility of the neutral version. But unless they are distinguished, it is illegitimate to appeal to Strawson's discussion in support of the AMI thesis rather than the Neutrality thesis that is its rival.

Suppose, though, that, once the distinction is appreciated, there are those who insist that however it may be with others, their introspection does support the Strawsonian version of the permeation thesis, rather than its neutral rival $?^{13}$ There is not much that I can say to counter such a sincere insistence. But I think it is questionable whether these people would be correctly describing - and not 'over-interpreting' - the deliverances of introspection. More significantly, though, since the AMI thesis is supposed to be a general thesis about ordinary (mature) perceptual experience, if the Strawsonian thesis were true only of some typical mature human perceivers, but not of other such perceivers, this would seriously weaken the force of these introspective arguments in favour of the AMI thesis. ${ }^{14}$

\footnotetext{
${ }^{12}$ These concepts would themselves be 'neutral' in the sense that they would apply to physical objects regardless of whether physical objects (trees, tables, etc.) are mind-independent or minddependent. This does not imply, however, that to possess such a 'neutral' concept one must have an appreciation of its ontological neutrality.

${ }^{13}$ Thanks to Craig French for raising this issue.

${ }^{14}$ It would also contradict Strawson's claim that his permeation thesis is true of 'the character of sensible experience as we all actually enjoy it' [ibid.: 45. Italics mine].
} 
Finally, we can consider the implications of Strawson's account for the case of an otherwise ordinary perceiver who is a convinced Berkeleian idealist. Would Strawson claim that his permeation thesis is true even of this Berkeleian perceiver - that in spite of the Berkeleian's convictions, his sensible experience is permeated by the very concepts of physical objects that he rejects? Or would Strawson claim, instead, that the Berkeleian's sensible experience is permeated by concepts of physical objects not realistically conceived, and thus differs significantly from that of the ordinary person (cf. Ayer [1979: 292])? Neither option seems very appealing. To the extent that they are not, this threatens the credibility of the Strawsonian permeation thesis.

\subsection{The 'argument from associated belief'}

As I have noted (section 1), Berkeley sometimes appears to concede that ordinary people believe that when they perceive a physical object they perceive something mindindependent (although he thinks that this belief is mistaken, and involves a contradiction). Take, then, someone who does hold this 'strangely prevailing' opinion about the nature of physical objects. Could such a person argue as follows?

(1) I am having a perceptual experience in which it seems to me that I am aware of a tree.

(2) I believe that trees are mind-independent objects.

Therefore:

(3) I am having a perceptual experience in which it seems to me that I am aware of a mind-independent object. 
If this argument were sound, it would appear to establish that, at least for someone who believes in the mind-independence of physical objects, that person's perceptual experience would satisfy the AMI thesis.

Unfortunately for the defender of the AMI thesis, however, the argument is invalid if its conclusion is interpreted in a way that would support the AMI thesis. It doesn't follow, from the fact that one has a perceptual experience that appears to be an awareness of an object, plus the fact that one believes that that object has a certain property, that one's perceptual experience appears to be an awareness of the object's having that property (or of the object as having that property). For example, if I have a visual experience that appears to be of a cat in the garden, and I believe that the cat is five years old, it does not follow that I have a visual experience that appears to be an awareness of the cat as having the property of being five years old.

But the AMI thesis under discussion here is not the thesis that one's perceptual experience seems to be an awareness of objects of which one also happens to believe that they are mind-independent. It is the thesis that it seems to be an awareness of them as mindindependent. The mind-independence has to be something of which one is, or at least appears to be, perceptually aware. (See section 2 above.) And (as the example of the cat shows) this is not guaranteed simply by one's possession of the belief that the object of which one appears to be perceptually aware has that property.

I shall return to this point in section 6 . For the present, it is enough to note that the argument considered above - what we might call 'the argument from associated belief' - is not a sound argument for the AMI thesis. 


\section{3 'Particular mind-independence'}

It is sometimes said that ordinary perceptual experience presents its objects as not depending for their existence on that particular perceptual episode, or as not depending for their existence on the perceiver who has the experience. (See, for example, Siegel [2006a: 356-7].) If this is true, it is certainly an important fact. But even if it could be established that ordinary perceptual experience has this feature, it would be a gross non sequitur to conclude, without further argument, that it has the AMI feature that is under discussion in this paper.

It hardly needs saying that neither the property of being independent of a particular perceptual episode nor the property of being independent of a particular perceiver is the same as the property of being independent of all perceptual episodes and all minds and perceivers. Let us call the first of these 'particular mind-independence', and the latter 'absolute mind-independence'. ${ }^{15}$

In suggesting (sections 2 and 3 above) that the AMI thesis appears to be in tension with Berkeleian idealism, I have, of course, assumed that the notion of mind-independence involved in the AMI thesis is that of absolute mind-independence. ${ }^{16}$ As is well known, Berkeley accepts that the physical objects that I perceive do not depend for their existence on my mind, or my current awareness of them. For example, the table that I now perceive could exist without my perceiving it, as long as some other mind perceives it [Principles 3].

\footnotetext{
${ }^{15}$ An anonymous referee has asked whether I assume that an object or feature is 'absolutely' mindindependent just in case it would figure in Williams's [1978] 'absolute conception' of the world. I make no such assumption, but shall not discuss the issue further here.

${ }^{16}$ By 'in tension with', of course I don't mean 'incompatible with', since there is the 'error theory' option discussed in section 3 above.
} 
Hence the following modified version of the AMI thesis is not in any tension with Berkeleian idealism:

APMI (Appearance of Particular Mind-Independence) thesis: Ordinary perceptual experience has the APMI ('Appearance of Particular Mind-Independence') property: that is, it appears to its subject that the experience is (or involves) an awareness of objects and features that do not depend for their existence on that experience or on its subject.

In other words, the APMI thesis, unlike the AMI thesis, does not imply that if Berkeleian idealism is true, introspection of our ordinary perceptual experience is systematically misleading as to the status of the objects that we perceive. ${ }^{17}$ For, according to Berkeley, ordinary perceptual experience really is typically an awareness of physical objects and features (such as trees and their properties) that could and do exist independently of our individual perception of them. What Berkeley denies, of course, is that these physical objects and features could exist independently of all minds and perceivers. Hence, unless supplemented with an argument for the conclusion that if perceptual experience has the APMI property, it must also have the AMI property, the appeal to the fact (if it is a fact) that ordinary perceptual experience has the APMI property is worthless as a reason for accepting the AMI thesis.

\footnotetext{
${ }^{17}$ This is not to say that Berkeley is committed to the APMI thesis. He could consistently hold that ordinary perceptual experience, as we introspect it, is neutral as to whether its objects have the property of particular mind-independence.
} 


\subsubsection{Ignoring the distinction between absolute and particular mind-independence}

Oddly enough, a failure consistently to observe the distinction between particular and absolute mind-independence is a feature of the discussion by Campbell and Cassam in their recent Berkeley's Puzzle [2014]. Oddly, because the book purports to be a discussion of the concept of a mind-independent physical object that Berkeley regards as incoherent.

Campbell and Cassam agree that Berkeley holds that we do not (and could not) have a (coherent) concept of a mind-independent physical object. ${ }^{18}$ Campbell and Cassam think that we do have this concept, and seek to explain how our possession of it is possible. And they undertake the further task of explaining how our possession of this concept is or could be grounded in our perceptual (sensory) experience. ${ }^{19}$

But now, the concept of mind-independence that Berkeley judges to be incoherent as applied to physical objects is, as we know, that of absolute mind-independence. One would therefore expect that the concept for which Campbell and Cassam seek a grounding in sensory experience is that of an absolutely mind-independent physical object. Yet both authors sometimes seem to lose sight of this, and use 'mind-independence' as a label for what I have called 'particular mind-independence'. Thus Campbell says:

For each of us, the visual experience in this case of joint attention . . . has to be characterized in terms of the object itself that both you and I are experiencing. It's implicit here that the object in question is mind-independent. It can't be internal to your

\footnotetext{
${ }^{18}$ Campbell and Cassam omit the qualification 'coherent'. But see note 9 above.

19 This is an additional task, because one might hold that the concept of a mind-independent physical object is a 'theoretical' concept that is not grounded in our sensory experience in the relevant sense. See Cassam, in Campbell and Cassam [2014: 116, 124ff.].
} 
mind, because it's what I am attending to. And it can't be internal to my mind, because it's what you are attending to. [Campbell and Cassam 2014: 68. Italics mine]

It does not follow, from the fact that the object is not dependent on the minds of either of two perceivers taken individually, that it is independent of the minds of all perceivers taken collectively. So if Campbell's argument here is to be cogent, 'mind-independent' must be taken in its 'particular mind-independence' sense, not its 'absolute mind-independence' sense.

As for Cassam, in the following passage he explicitly identifies mind-independence with what I have called 'particular mind-independence':

a natural question is: does my [current visual] experience [of the tree] represent the tree as mind-independent? Many representationalists would say that it does. According to Susanna Siegel, for example, 'the objects we seem to see are presented to us as subjectindependent' ... What Siegel calls subject-independence is what I call mindindependence; it is 'the independence of a thing's existence from the experience that the subject has in seeing it ...' [ibid.: 161, quoting Siegel [2006a]. Some italics added]

But Cassam has surely slipped up in making the claim that I have emphasized in the last sentence of this quotation. Contrary to what he says here, subject-independence (a form of particular mind-independence) is not what he means by the term 'mind-independence' in this book. 
Elsewhere in the book Campbell and Cassam show that they are aware that it is absolute mind-independence that is relevant to their anti-Berkeleian project. ${ }^{20}$ So the passages I have quoted appear to be aberrations. Nevertheless, perhaps the fact that these passages occur at all in their book is a symptom of how easy it is to forget that particular mind-independence does not amount to absolute mind-independence.

\subsubsection{From particular mind-independence to absolute mind-independence?}

The preceding discussion obviously raises the question whether a bridge could be built that would allow one to move from the APMI thesis to the AMI thesis, where the latter is understood as a thesis about absolute mind-independence.

It is beyond the scope of this paper to explore this possibility. However, this project appears to be a formidable research programme, and one that, as far as I am aware, no one has successfully executed. ${ }^{21}$ Thus the credentials of the APMI thesis as a potential basis for the AMI thesis are, to say the least, unproven.

\section{Taking stock}

One possible reaction to my discussion so far is this. It might be suggested that many of those whom I take to have claimed (or to have claimed that others claim) that the AMI

\footnotetext{
${ }^{20}$ See, for example, Campbell [ibid.: 28, 32, 97, 181]; Cassam [ibid.: 128, 150-1].

${ }^{21}$ It would be instructive to compare this project with an attempt, in meta-ethics, to build a bridge between (a) the thesis that moral facts are independent of the moral sensibility of any particular individual and (b) the thesis that moral facts are independent of the moral sensibilities of all human beings collectively $-\mathrm{a}$ form of moral realism. Thanks to Robert Frazier for suggesting this comparison.
} 
thesis is true have simply been imprecise in expressing their views. Perhaps many of them have been using 'mind-independent objects' to mean 'ordinary physical objects', without considering a Berkeleian interpretation of 'ordinary physical object'. Perhaps some of them intended nothing stronger than that it seems to us that the objects we perceive have the property of particular (as opposed to absolute) mind-independence.

Even if this were the most that my negative arguments have revealed, this would be a significant result. It is an important philosophical question whether our perceptual experience really does seem to us to involve a mind-independent world, in the 'absolute' sense of that expression. And making progress with answering this question requires that we distinguish it from others with which it might be conflated.

I take it, though, that at least some who have endorsed what appear to be versions of the AMI thesis really do intend to advocate it in its strict, literal, and absolute sense. In the remainder of this paper, I shall, albeit briefly, consider the prospects for defending this view.

\section{How plausible is the AMI thesis, anyway?}

My first comment is that the AMI thesis, so understood, actually seems to me extremely implausible. Given the points noted in section 4.2 above, there is a puzzle about how mindindependence could figure in our perceptual experience in a way that the thesis suggests. The AMI thesis seems to require that the property of mind-independence (in its 'absolute' sense) be a property of which it appears to us that we are perceptually aware. But how could this claim be defended? 
A straightforward suggestion would be that mind-independence figures in our awareness as a perceptible property. But this seems crazy. The property of mind-independence (in the absolute sense) is that of being capable of existing unperceived or unthought of (being capable of extra-mental existence). And I don't see how it could be right to say that, in being (apparently) perceptually aware of a tree - say, in a visual experience - I am (apparently) perceptually aware of its mind-independence. Do trees look mind-independent? Does it even make sense to suggest that they do?

My problem is not that (absolute) mind-independence is a modal property. I do not find problematic the suggestion that something can look dangerous, or fragile, for example, although these are modal properties. Nevertheless, it is implausible to suppose that all modal properties are genuinely perceptible. ${ }^{22}$ So in claiming that (absolute) mindindependence is not a perceptible property, I am not pleading for an exception to an otherwise universal rule.

On the other hand, if the AMI thesis is not claiming that mind-independence, as such, seems to be a perceptible feature of the objects that we seem to perceive, what exactly is it saying? How does it differ from the thesis that when we have a perceptual experience, we have the associated belief that the objects of which we appear to be aware are mindindependent? (Cf. section 4.2 above.)

Perhaps the answer is this: although mind-independence is not itself a perceptible property, there is some other perceptible property, or set of properties, that we appear to be aware of in perceptual experience, and it is in virtue of this that it is appropriate (even if,

\footnotetext{
${ }^{22}$ The issue of which properties are genuinely perceptible cannot be examined in detail here. For some discussion, see Gendler and Hawthorne [2006: 10-11], and Siegel [2006b, 2016].
} 
perhaps, a bit misleading) to describe our perceptual experience as appearing to us to be the awareness of mind-independent objects.

The next question, obviously, is twofold. Are there such properties? And, if so, what are they? This is a huge issue, and I cannot hope to resolve it here. But I shall conclude this paper with a (sceptical) consideration of some candidates for this role suggested by Campbell and Cassam in their recent joint work [2014].

\section{Perceptual experience and absolute mind-independence}

Campbell and Cassam [2014] are not primarily concerned to defend the version of the AMI thesis that has been the focus of my discussion in this paper - its 'introspection' version (cf. section 2.2 above). I take it, though, that both of them aim to defend the "phenomenal character' version of the AMI thesis that I distinguished in section 2. For they seek to ground our conception of a mind-independent physical object in our sensory experience, by attempting to identify features of that experience that present, or represent, the mindindependence of the physical objects that we perceive. ${ }^{23}$ Moreover, as I have emphasized (section 4.3.1), their anti-Berkeleian project makes sense only on the assumption that the relevant notion of mind-independence is the absolute one. Their project is thus relevant to the defence of the 'introspection' version of the AMI thesis that is the focus of my discussion. For if there are features of the phenomenal character of our perceptual experience that genuinely ground a conception of absolute mind-independence, then it is

\footnotetext{
${ }^{23}$ Cassam expresses reservations about the project, because he is not convinced of the 'experientialist' assumption on which it relies [ibid: 116, 124-35]. In most of the work, though, he goes along with this assumption.
} 
reasonable to suppose that, in introspectively reflecting on that phenomenal character, it would seem to us that we are aware of a mind-independent (in the sense of 'absolutely mind-independent') world.

I cannot attempt here to do justice to their extensive and sophisticated discussion. However, I think that there are serious problems about whether the candidates that Campbell and Cassam propose for the 'mind-independence' role can do the job required of them.

Both Campbell and Cassam argue that mind-independence does 'show up' in our perceptual experience, although they have very different theories of how this is possible. According to Campbell, the key to the mind-independence of physical objects is a kind of causal autonomy (or 'causal unity') - their possession of an 'immanent causal structure' that constitutes their identity [2014: 97]. For example:

[It is] central to our conception of [physical] objects as mind-independent ... [that we] think of [them] as internally causally connected: the way an object is later depends not only on how other things impinge on it, but on the way the object itself was earlier. And . . . this internal causal connectedness of the object, which is independent of its relation to a mind, is what constitutes the identity of the object . . . [ibid.: 26. Italics mine]

According to Campbell's 'relational' conception of perceptual experience, the mindindependence reveals itself in perceptual experiences in virtue of those experiences' having (in favourable cases) a nature that is in part constituted by relations to the mind-independent objects that possess this causal autonomy (causal unity) property (for example, [ibid.: 71, 98]). 
According to Cassam, the key to the mind-independence of physical objects is that they are constant, persisting, and material. According to his 'representationalist' conception of perceptual experience, the mind-independence of physical objects 'shows up' in perceptual experiences which 'display' it [ibid.: 165] because those experiences represent the objects as mind-independent 'by representing them as constant, persisting, and material' [ibid: 164]. Moreover, Cassam implies that it is sufficient, for an experience to represent an object as material, that it represent it as having primary qualities: 'My sensory experience represents the tree as shaped, located, and solid, and thereby represents it as a material object' [ibid.: $163]$.

Although Campbell and Cassam may regard these properties as actually constituting mind-independence, I shall describe them as 'surrogates for mind-independence'. This allows me to ask two questions: (1) Do the properties invoked by Campbell and Cassam as surrogates for mind-independence really show up in our perceptual experience in the relevant way? (2) Are these properties really fit to play the surrogacy role?

I think that there are difficulties about whether even the first requirement is met. However, I shall focus on the second.

If the properties in question are to be suitable surrogates for the property of mindindependence, they had better be sufficient for mind-independence. They had better be properties that physical objects would not have unless they were mind-independent. Once this requirement is made explicit, though, I think it reveals a severe difficulty for Campbell's and Cassam's accounts, given that what is at issue is the absolute mindindependence that Berkeley denies to physical objects.

What properties would physical objects have if Berkeleian idealism were true - that is, if physical objects (trees, tables, etc.) were mind-dependent collections of ideas, sustained 
not only by the perceptual experience of humans (and other finite minds), but also ultimately by the mind of God? Crucially, would such Berkeleian physical objects lack any of the properties that Campbell and Cassam treat as surrogates for mind-independence?

With regard to Campbell's account, I concede that Berkeley would deny that, strictly speaking, a physical object has an immanent causal structure - that there is 'causality that works within [the] object over time' in such a way that its later states are directly dependent on its earlier states [ibid.: 97]. However, this is a consequence of Berkeley's 'volitional' conception of causality - according to which only minds can be causes [Principles $102 \mathrm{ff}$.] - rather than an implication of his idealist construal of physical objects as collections of ideas. ${ }^{24}$ Also, since Berkeley thinks it legitimate to 'speak with the vulgar' in ordinary causal discourse, rather than denying that fire heats, or that water cools [Principles 51], I assume that he would be willing - even given his volitional theory of causality - to say that a physical object's later states do depend causally on its earlier states, as long as this is not literally interpreted.

Nor does it help Campbell's case to insist that the causal unity and resulting identity conditions that he attributes to physical objects can be characterized without reference to minds, as in the following passage:

When we characterize the identity of the object in this way [that is, in terms of the causal dependence of the way it is later on the way it was earlier], we do not need to bring in its relation to a mind. [2014: 29. Italics mine]

${ }^{24}$ Cf. Cassam's criticism of Campbell in Campbell and Cassam [2014: 128, 150]. 
The most that would follow from this is that such identity conditions could be possessed by mind-independent objects, not that they could be possessed only by mind-independent objects. Hence, when Campbell concludes the passage I have quoted above with the sentence 'That is how we have the conception of the object as mind-independent' [ibid. Italics mine], this appears to be a non sequitur. How could our conception of an object as mind-independent be explained by our grasp of a property that could be possessed by mindindependent objects, if that property could also be possessed by mind-dependent objects? To justify the inference, Campbell needs the additional premise that the identity conditions of mind-dependent objects (by which he evidently means the conditions for their sameness over time - their persistence conditions) essentially involve dependence on minds. Campbell does appear to hold that this is so:

If an object is mind-dependent, if for example the object is constitutively dependent on your mind, or the mind of God, then the way things are later with that object depends on how things are then with your mind, or God's . . [ibid.: 97]

However, as far as I can see, Campbell provides no argument for this crucial claim. And I see no reason to accept it. Yet without this claim, Campbell's thesis that the sameness over time of a mind-dependent object (unlike a mind-independent object) cannot be constituted by 'an immanent causal structure - the causality that works within an object over time' [ibid.] is unsustained. ${ }^{25}$

\footnotetext{
${ }^{25}$ Suppose that, in saying that a physical object's 'identity' is constituted by such an internal causal structure, Campbell meant, by 'its identity', what makes it the object that it is, rather than (as I have assumed) what constitutes its sameness (identity) over time? This would not help Campbell, given
} 
I conclude that Campbell has not provided a convincing argument that the properties that he regards as sufficient for the mind-independence of physical objects could not belong to physical objects construed, in Berkeleian fashion, as mind-dependent collections of ideas.

Turning to Cassam, our question is whether Berkeleian physical objects would lack any of the properties on Cassam's list. Unfortunately for Cassam's account, it looks as if the answer is 'no'. Berkeleian physical objects surely have the properties of constancy and persistence. They have primary qualities such as shape and solidity (although Berkeley denies that there is an ontological distinction between such properties and so-called 'secondary qualities' such as colour). And Berkeley does not deny that physical objects are located in space (see Walker [1985: 122-3]). Hence if, as Cassam suggests, it is sufficient for being a material object to have primary qualities such as shape, solidity, and location [2014: 163], then Berkeleian physical objects pass the test for being material objects too. ${ }^{26}$

At this point, I anticipate an objection. Perhaps Campbell and Cassam would protest that my argument for the inadequacy of their surrogate mind-independence properties depends on my interpreting those properties in an eccentric way. They might claim that on a proper interpretation of the nature of those properties, they could not belong to Berkeleian physical objects, and hence are genuinely sufficient for absolute mind-independence after all. However, this reply would only push the wrinkle in the carpet to another place. Campbell and Cassam would then face the task of establishing that it is the properties interpreted as

that (as I have argued) such an internal causal structure could belong to physical objects even if they were mind-dependent collections of ideas.

${ }^{26}$ Berkeley denies that physical objects are material only because he does not take the properties cited by Cassam to be sufficient for being material. 
they interpret them, rather than their Berkeleian counterparts, that show up in our perceptual experience.

My verdict is that it is doubtful that either Campbell or Cassam has identified properties that both are plausibly regarded as presented (or represented) in our perceptual experience, and also are plausibly sufficient for (absolute) mind-independence - that is, the independence of all minds that Berkeley denies to physical objects. If this is right, any defence, based on their discussion, of the claim that our ordinary perceptual experience seems to present the world to us as mind-independent in a way that would be misleading if Berkeleian idealism were true is very far from secure.

I conclude that Campbell and Cassam may be, so to speak, 'Berkeleying up the wrong tree'. But this point extends beyond a criticism of Campbell and Cassam. My challenge to their project seems likely to confront any attempt to find, in our ordinary perceptual experience, the presentation (or representation) of properties that physical objects would not possess unless they were absolutely mind-independent, rather than being, as Berkeley maintains, mind-dependent collections of ideas.

\section{Conclusion}

I submit that the challenge posed to the AMI thesis by the rival Neutrality thesis (introduced in section 3 above) still stands. We have found no good reason to think that ordinary perceptual experience has the AMI property - the property of seeming to its subject to be (or involve) the awareness of a mind-independent world. And we have found good reasons 
to be suspicious of this claim. At the very least, we can conclude that the apparently widespread assumption that the AMI thesis is true is without adequate foundation. ${ }^{27}$

\section{References}

Ayer, A.J. 1979. Replies, in Macdonald, ed., 1979: 277-333.

Berkeley, G. 1710. The Principles of Human Knowledge, in Robinson, ed., 1996. (Referred to in the text as 'Principles'.)

Campbell, J. and Q. Cassam 2014. Berkeley's Puzzle: What Does Experience Teach Us? Oxford: Oxford University Press.

Crane, T. and C. French 2017. The Problem of Perception, The Stanford Encyclopedia of Philosophy (Spring 2017 Edition), ed. E.N. Zalta, URL = <https://plato.stanford.edu/archives/spr2017/entries/perception-problem/>.

Farkas, K. 2013. Constructing a World for the Senses, in Phenomenal Intentionality, ed. U. Kriegel, New York and Oxford: Oxford University Press: 99-115. DOI:

10.1093/acprof:oso/9780199764297.003.0006

\footnotetext{
${ }^{27}$ I thank audiences at the Central European University at Budapest, and the Universities of Oxford, Southampton, Otago, Canterbury (NZ), and Glasgow, where various earlier versions of this paper were delivered. For comments I also thank Robert Frazier, Mark Jago, Harold Noonan, Howard Robinson, Ralph Walker, Christopher Woodard, and two anonymous referees. I am especially grateful to Craig French, for invaluable discussion as well as extensive comments on several drafts.
} 
Foster, J. and H. Robinson, eds, 1985. Essays on Berkeley: A Tercentennial Celebration, Oxford: Clarendon Press.

Gendler, T.S. and J. Hawthorne, eds, 2006. Perceptual Experience, Oxford: Clarendon Press.

Macdonald, G.F., ed., 1979. Perception and Identity: Essays Presented to A.J. Ayer with his Replies to them, London: Macmillan.

Martin, M.G.F. 1997. The Reality of Appearances, in Thought and Ontology, ed. M. Sainsbury, Milan: FrancoAngeli; reprinted in Disjunctivism: Contemporary Readings, ed. A. Byrne and H. Logue, Cambridge, MA: The MIT Press, 2009: 91-115. Page references are to the reprinted version.

Martin, M.G.F. 2002. The Transparency of Experience, in Mind \& Language 17/4: 376425.

Martin, M.G.F. 2006. On Being Alienated, in Gendler and Hawthorne, eds, 2006: 354-410.

Nudds, M. 2009. Recent Work in Perception: Naïve Realism and its Opponents, Analysis Reviews 69/2: 334-46.

Robinson, H., ed., 1996. George Berkeley: Principles of Human Knowledge and Three Dialogues, Oxford: Oxford University Press.

Siegel, S. 2006a. Subject and Object in the Contents of Visual Experience, The Philosophical Review 115/3: 355-88.

Siegel, S. 2006b. Which Properties are Represented in Perception?, in Gendler and Hawthorne, eds, 2006: 481-503.

Siegel, S. 2016. The Contents of Perception, The Stanford Encyclopedia of Philosophy (Winter 2016 Edition), ed. E.N. Zalta, URL = <https://plato.stanford.edu/archives/win2016/entries/perception-contents/>. 
Soteriou, M. 2016. Disjunctivism, London: Routledge.

Strawson, P.F. 1979. Perception and its Objects, in Macdonald, ed., 1979: 41-60.

Tipton, I.C. 1974. Berkeley: The Philosophy of Immaterialism, London: Methuen \& Co. Ltd.

Walker, R.C.S. 1985. Idealism: Kant and Berkeley, in Foster and Robinson, eds, 1985: 10929.

Williams, B. 1978. Descartes: The Project of Pure Enquiry, Harmondsworth: Penguin Books Ltd. 